\title{
FEATURE
}

\section{Wikipedia: Librarians' Perspectives on Its Use as a Reference Source}

Mention Wikipedia in a group of people and a lively discussion is sure to follow with terms such as peer-review, editing policies, and Web 2.0 entering the conversation. Wikipedia is the open access, Web 2.0 encyclopedia that is harnessing the power (and knowledge) of the masses and making it freely available to the Internet audience. With open access, problems have appeared and solutions have been implemented; however, many netizens (network citizens) are only aware of the negative and high profile misuses of Wikipedia, skewing their view of this knowledge repository. This paper studies how one group of information seekers, librarians, is utilizing this freely accessible web resource in their work, and how positive and negative awareness affects this usage. Usage statistics, awareness statistics, and gender differences for Wikipedia usage are presented in this paper and discussed. Comparisons of librarian statistics to previously published data on university faculty and student usage of Wikipedia are presented. It is established that librarians have greater awareness of negative issues surrounding Wikipedia than of positive issues. This awareness drives usage of Wikipedia in personal and professional settings. Results also indicate that there are no major gender differences in awareness of positive and negative issues concerning Wikipedia, but that males tend to use Wikipedia more than females, confirming the results of previous studies.

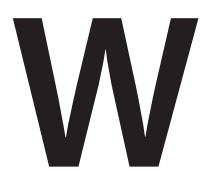
ikipedia has had a rocky ride over its first decade of existence. As one of the largest knowledge repositories on the web, Wikipedia holds a topten position with Internet users, sharing this list with sites such as Google, Facebook, and YouTube. Wikipedia's reputation has been fueled by negative reports in the media (the Seigenthaler case and the Essjay incident being examples) that lead users to be skeptical of the site's content. Lesser known are the positive outcomes (no more anonymous article creation, protected pages) which have been Wikipedia's responses to problems in its policies.

These negative reports and Wikipedia's responses in editing policies have led users, in particular, librarians, to hold fairly strong viewpoints about the information quality in Wikipedia, prompting much discussion on how to manage this knowledge resource in the age of the web, specifically in the age of Web 2.0 (user generated content) tools.

Librarians are information seekers, both for themselves and for library patrons. Usage of web resources has become commonplace in the twenty-first

\section{Johnny Snyder}

Johnny Snyder (josnyder@ coloradomesa.edu) is Professor of Computer Information Systems, Colorado Mesa University, Grand Junction, Colorado
Reference \& User Services Quarterly, vol. 53, no. 2, pp. 155-63 (c) 2013 American Library Association. All rights reserved.

Permission granted to reproduce for nonprofit, educational use. 


\section{FEATURE}

century, so information literacy (being able to locate and evaluate the quality of information) on the web becomes ever more critical in an information-based society. Librarians, as public guides to the information highway, need to understand the types of resources available to the public online, and need to understand the pros and cons of these resources, to better assist their patrons in becoming information literate.

The popularity of Wikipedia on the web has been well documented. ${ }^{1}$ How librarians are using Wikipedia in their work environment has not been heavily studied. This paper examines librarians' perspectives on Wikipedia and benchmarks usage statistics and awareness of positive and negative issues concerning Wikipedia for a librarian study group.

\section{LITERATURE REVIEW}

A more exhaustive literature review of issues surrounding Wikipedia, the history of Wikipedia, and current research threads concerning Wikipedia can be found in the paper: "Wikipedia as an Academic Reference: Faculty and Student Viewpoints."

Maness recognized that Web 2.0 technologies were altering the information literacy landscape and defined "Library 2.0" as a new paradigm for librarianship. ${ }^{3}$ This definition included web-based technologies and web-based library services such as synchronous messaging, streaming media, blogs and wikis, social networks, tagging, RSS feeds, and mashups as tools for today's libraries and librarians. Wikipedia is specifically mentioned as a site that librarians are cautious about due to its open editing policies. However, Maness also states that "this of course does not eliminate their value, it merely changes librarianship, complicates collection development and information literacy instruction." ${ }^{4}$ Maness advocates for using Wikipedia, but also warns that librarians need to understand Wikipedia and be critical in using it.

Shachaf compares Wikipedia's reference desk services to traditional reference desk services using the SERVQUAL quality variables: reliability (accuracy, completeness, and verifiability), responsiveness, and assurance. ${ }^{5}$ The study revealed that "the Wikipedia Reference Desk provides answers that are as accurate as those that traditional (and digital) reference librarians provide." Shachaf concludes with the statement "perhaps social reference is one of the "Web 2.0 world [that] can and should appear as a part of formal library and information science courses."' Anderson agrees, expressing concern that information education (library science) is threatened with becoming irrelevant, partly due to the rate of change occurring in digital environments. ${ }^{8}$

East, in a paper discussing subject encyclopedias in the digital age, writes, "Educators became increasingly concerned about the dubious quality of the information that their students were using, and librarians began to see a new role for themselves in teaching the evaluation of information found on the web" while discussing information retrieval on the Internet. ${ }^{9}$ East points out that with the digitization of information, librarians must keep appraised of the changes and challenges of the digital information world. ${ }^{10}$

In a paper assessing the quality of Wikipedia articles, West and Williamson assert the following:

It seems that the ongoing professional discussion about whether Wikipedia is good or bad is irrelevant. It exists; it is being used. It is a logical starting point for research for many individuals; it is particularly good as a definition tool that acts as a springboard for further research. ... Wikipedia has a place within the context of information gathering. ${ }^{11}$

This statement illustrates the need for what Michael Stephens calls a next-generation librarian, one who is familiar with Web 2.0 tools and social software, and one who can train library users (and other librarians) on the use of these tools for information retrieval and evaluation. ${ }^{12}$

Rand advocates for using Wikipedia to teach digital literacy skills and exploring information quality issues. Rand also points out that freely accessible articles online are more frequently referenced in Wikipedia because they can be linked on the Wikipedia article's page. ${ }^{13}$ These links to other information sources are one of the features that make Wikipedia a popular starting point for many students and faculty. ${ }^{14}$ Murley notes that the greatest value of a Wikipedia article could be its links to relevant sources outside of Wikipedia, something that many traditional encyclopedias lack. ${ }^{15}$

Information seekers (students, faculty, librarians, others) enjoy the "information security" that peer-review brings. In an article comparing Wikipedia to Scholarpedia (a peer reviewed online encyclopedia) Stankus and Spiegel compare reference lists between articles with the exact same title. ${ }^{16}$ They find that both encyclopedias offer "references to solid materials and that any differences in quality indicators represent matters of degree rather than any clear-cut advantage."17 This is an addition to the work of Giles published in Nature that compared Wikipedia articles to Encyclopedia Britannica online articles and found that the two were similar, and that the minor errors in both "did not seriously affect the overall value of the articles." ${ }^{18}$ One of the issues of concern is given in table $1 .{ }^{19}$

Table 1 illustrates what is becoming known as "the power of the masses" that has taken shape under the guise of web 2.0. While peer-review is preferred, the time to build a peerreviewed encyclopedia can be lengthy, and the amount of work involved staggering. Netizens have built Wikipedia at the rate of 367,575 articles/year, an example of wikinomics (mass collaboration) at work. These issues (time and work) are why the online peer-reviewed encyclopedias have so few entries. In addition to the power of the masses (the existence of peer review could be argued in an open editing environment) there is an inherent power in linked data as more and more researchers turn to the web as their initial research tool. Schreur states that "linked data has the potential to revolutionize the academic world of information creation and exchange. ${ }^{" 20}$ Understanding the speed at which information can 
Table 1. Comparison of Growth in Encyclopedias

\begin{tabular}{lccc}
\hline Encyclopedia & Number of Articles (peer reviewed) & Date of Inception & Articles/Year (peer reviewed) \\
Scholarpedia & $1,740(709)$ & 2006 & $348(142)$ \\
Citizendium & $15,893(156)$ & 2006 & $3,179(31)$ \\
Wikipedia & $3,675,746(3,321)$ & 2001 & $367,575(332)$ \\
Britannica & $228,274(228,274)$ & $1768 \sim 1771$ & $947(947)$ \\
\hline
\end{tabular}

be created in the digital universe and the complications with information literacy at this speed (is the article accurate? is the article complete? does the article have proper sources?) of creation is critical for librarians to understand to better assist patrons in their information searches. Wikipedia illustrates this phenomenon and has given researchers (and librarians) much to discuss over the past years.

Demographic differences in Wikipedia usage have also been the subject of study by authors. Lim and Kwon found that males tend to use Wikipedia more than females, enhancing their information literacy skills in the Web 2.0 environment. The findings also indicate that males use Wikipedia more than females for entertainment or idle reading, but no differences were observed in Wikipedia usage for academic purposes. ${ }^{21}$ Waller studies Wikipedia usage based on lifestyle groups (privileged, academic, young, ... . farming stock, suburban, community disconnect) and found that Wikipedia users constitute higher income and higher educational attainment groups. ${ }^{22}$

Waller also notes that more research is needed on how Wikipedia is actually used based on examining different user groups. This paper begins to address these concerns and adds to the literature by presenting usage statistics for a group of librarians and compares these usage statistics to previously gathered statistics for university faculty and students. ${ }^{23}$

\section{RESEARCH METHOD}

A survey instrument for librarians was developed in the fall semester of 2010 (Appendix) and distributed to all library directors in a western United States library consortium. The consortium is composed of nine academic libraries (public schools, colleges) and thirteen public libraries. This convenience sample was selected because the author's institution belongs to the consortium, and name recognition was assumed to increase the response rate. Each library director distributed the surveys to their staff, then collected and returned them to the researcher. There are 22 libraries in the consortium, and ten of these libraries responded to the survey yielding 58 usable surveys. The survey respondents included:

- seven reference librarians;

- six adult/youth services librarians;

- two electronic resource librarians;

- five directors;

- four technical services librarians;
- $\quad$ one distance services librarian; and

- 23 respondents who did not report their job title.

It is interesting to note that the job titles of some librarians include technical services, distance services, and electronic resource, indicative of the trend toward online and electronic needs of the modern library.

This research study explores the following questions:

- Are librarians using Wikipedia?

- Are there gender differences in Wikipedia usage in the librarian group?

- Are there usage differences between school year and nonschool year times?

- What are librarians using Wikipedia for?

- How do librarians view Wikipedia as an information source?

- How aware are librarians of positive and negative issues surrounding Wikipedia?

- How do librarian statistics compare to university faculty and student results?

Questions concerning "awareness" of positive (page rank features for example) and negative (vandalism of pages for example) issues were incorporated into the survey to explore their effects on usage patterns of Wikipedia. Descriptive statistics are used to explore librarians' perceptions of Wikipedia and their usage statistics for this web-based information resource. The survey instrument primarily collected Likert scale data; so much of the data discussion is centered on non-parametric tests of medians. For discussion purposes, the mean and standard deviation are reported for some variables as well. The test results are computed using SPSS, and the results are reported in the style of Field. ${ }^{24}$

\section{RESEARCH FINDINGS}

\section{Librarian Results}

There were 58 usable surveys returned from the librarian group. Of these, ten (17 percent) librarians reported that they do not use Wikipedia, while 48 (83 percent) reported that Wikipedia is used in some fashion. These results align with those of Luyt, Ally, Low, and Ismail who found that a majority of librarians in Singapore use Wikipedia. ${ }^{25}$ The reasons for non-usage of Wikipedia are given in figure 1 . These also align closely with the results of Luyt, et al., indicating 


\section{FEATURE}

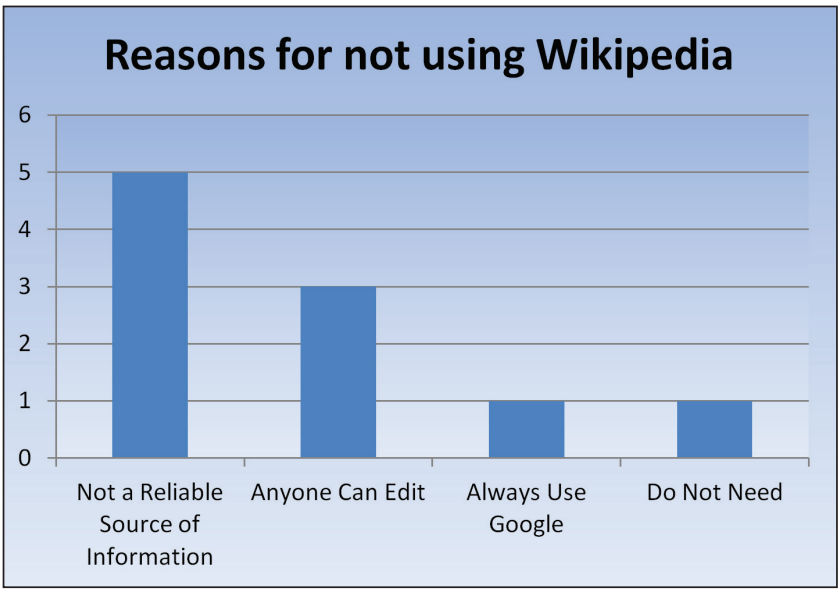

Figure 1. Reasons for not Using Wikipedia

Table 2. Librarian Wikipedia Usage Statistics

\begin{tabular}{lccc}
\hline Usage (times/week) & n & median & mean \\
During school year & 47 & 2 & 2.94 \\
During semester breaks & 47 & 1 & 2.12 \\
\hline
\end{tabular}

that apprehension for Wikipedia use cuts across cultural boundaries. ${ }^{26}$

For the remainder of the section, the discussion centers on the descriptive statistics from the 48 surveys returned by Wikipedia users (one respondent declined to report usage data, reducing $n$ to 47 in some tables).

Table 2 indicates that librarians use Wikipedia more during the school year (both mean and median) than during semester breaks. This is confirmed using a Wilcoxon signedrank test for the difference between two medians, $\mathrm{T}=20, p$ $<0.001, r=-0.53$. This difference (large effect in the language of Field, 2009) could be due to assisting school-age individuals with research for course assignments during the school year. This agrees with the results of Luyt, Zainal, Mayo and Yun who found that "over the long term, most respondents use Wikipedia only for school work."27 As many consortium librarians work with school-age populations, this difference in school year versus non-school year usage pattern is not unexpected. The differences in the mean and median values are due to the presence of three outliers (heavy Wikipedia users) in the data set. The assertion that librarians might be assisting school-age populations is also supported by figure 2 , Wikipedia usage statistics as collected by Compete.com. ${ }^{28}$ Figure 2 shows a drop in usage during the summer months, when many students are not attending classes, and a less pronounced drop during the semester break in December and January.

Differences in Wikipedia usage by gender are explored in table 3.

Naively, it appears that male librarians in this sample, on average, tend to utilize Wikipedia more than female librarians. A Mann-Whitney test supports the hypothesis that males

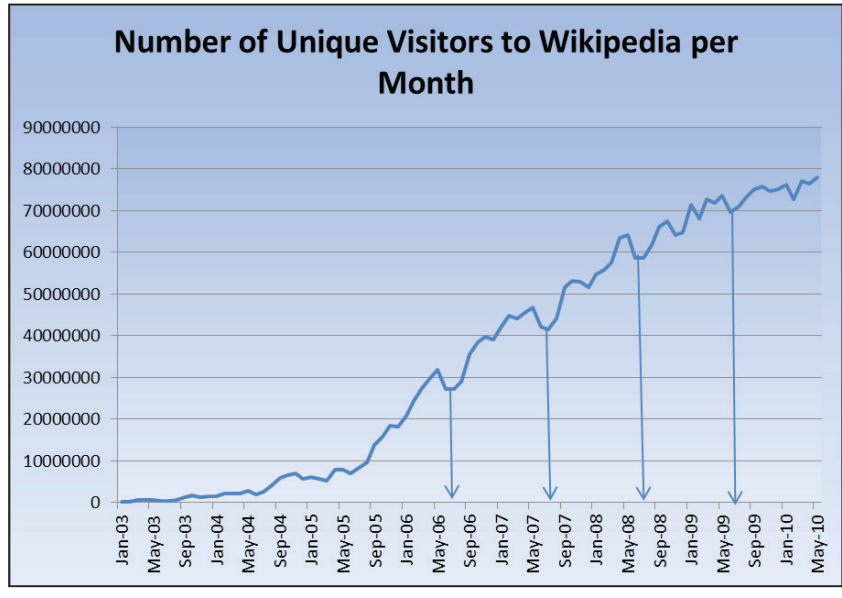

Figure 2. Number of Unique Visitors to Wikipedia

Table 3. Librarian Wikipedia Usage Statistics by Gender

\begin{tabular}{llccc}
\hline \multicolumn{2}{l}{ Usage (times/week) } & n & median & mean \\
During School & Male & $12(26 \%)$ & 2.5 & 4.46 \\
Year & Female & $35(74 \%)$ & 2.0 & 2.41 \\
\multirow{2}{*}{ During } & Male & 12 & 1.75 & 3.58 \\
Semester Breaks & Female & 35 & 1.0 & 1.61 \\
\end{tabular}

use Wikipedia more during the school year ( $M d n=2.5$ times/ week) than do females ( $M d n=2.0$ times/week), $\mathrm{U}=135.5$, $z=-1.889, p<0.05, r=-0.28$, while there is no difference in usage based on gender during semester breaks ( $M d n=1.75$ for males, $M d n=1.00$ for females) $\mathrm{U}=149.0, z=-1.520, \mathrm{p}$ $>0.05, r=-0.22$. Overall, gender has a moderate effect on the usage of Wikipedia. ${ }^{29}$ These results agree with the findings of Lim and Kwon (2010) regarding gender differences in Wikipedia usage - males tend to use Wikipedia more than females. A study by the Wall Street Journal found that only 13 percent of contributors to Wikipedia articles are women, further indicating that males tend to use and contribute to Wikipedia more than females. ${ }^{30}$

Table 4 summarizes how librarians in this study utilize Wikipedia

Most librarians, from the study group, who use Wikipedia, are using it for research and independent learning. Reasons listed for "other" uses of Wikipedia include: it pops up quickly, for the links/references, quick overview, current/ popular culture topics. While librarians use Wikipedia for the reasons listed in table 4, they seem to be reluctant to use Wikipedia to assist library patrons in finding information (question 4 on the survey-see Appendix). These statistics are presented in table 5 .

A Mann-Whitney test reveals that there is no difference, based on gender, for using Wikipedia to assist library patrons ( $M d n=0.00$ times/week for males, $M d n=0.50$ times/ week for females), $\mathrm{U}=176.0, z=-0.882, p>0.05, r=-0.13$, indicating a minimal effect (non-significant) of gender on 
Table 4. Librarian Usage of Wikipedia

\begin{tabular}{llll}
\hline Type of Usage & Yes & No & $\begin{array}{l}\text { No } \\
\text { Answer }\end{array}$ \\
Research & $30(63 \%)$ & $15(31 \%)$ & $3(6 \%)$ \\
Independent learning (pleasure) & $43(90 \%)$ & $5(10 \%)$ & $0(0 \%)$ \\
Alternate Types of Usage & & & \\
Initial research on a topic & 24 & 24 & \\
General topic review & 34 & 14 & \\
External links to topic & 26 & 22 & \\
Other & 5 & 43 \\
\hline
\end{tabular}

Table 5. Librarian Usage of Wikipedia to Assist Library Patrons

\begin{tabular}{llcc}
\hline Usage (times/week) & & n & median \\
Assisting Library Patrons & Male & 12 & 0.0 \\
& Female & 35 & 0.5 \\
\hline
\end{tabular}

using Wikipedia to assist library patrons. Table 6 reports how librarians view Wikipedia as a source of information, and how aware librarians are of positive and negative issues surrounding Wikipedia.

The results in table 6 indicate that librarians are neutral on their viewpoint toward Wikipedia as an authoritative source of encyclopedic information, but view Wikipedia positively as a source of general information, enforcing the increasingly popular idea that Wikipedia is a great place to start, but a poor place to finish. Testing for differences between genders (Mann-Whitney) for the categories in table 6 yielded no significant differences in views or awareness.

Evaluating the maximum awareness and minimum awareness (as measured by the medians) it appears that librarians are keenly aware that articles can be edited by "anyone" (a negatively perceived feature) but much less aware of the article rank feature (a positively perceived feature) of Wikipedia.

\section{Librarian, Faculty, Student Comparison}

In a previous paper, a survey instrument similar to the librarian survey instrument was given to faculty ( $\mathrm{n}=80$; non-users $=24$, users $=56)$ and students $(\mathrm{n}=469$; non-users $=110$, users $=359)$ at a medium sized western US university. ${ }^{31}$ In this section results from the three survey instruments are compared to evaluate differences in usage patterns and awareness issues between the three groups. Figure 3 illustrates the non-user versus user percentages for the groups.

Figure 3 illustrates that survey respondents prefer to use Wikipedia as a web-based source of information with ratios of 2.33 to 1 (faculty), 3.26 to 1 (students), and 4.80 to 1 (librarians). This indicates that librarians in this study
Table 6. Librarian Statistics for Awareness and View Categories

\begin{tabular}{lcccc}
\hline Category & n & Median & Mean & s \\
View_as_encyclopedic_ & 48 & 3.0 & 3.14 & 0.84 \\
information & & & & \\
View_as_general_ & 48 & 4.0 & 3.67 & 0.86
\end{tabular}
information

$1=$ very negatively, $3=$ neutral, 5 = very positively

\begin{tabular}{lcccc}
\hline Aware_edited_anyone & 48 & 5.0 & 4.0 & 0.92 \\
Aware_controversial & 48 & 4.0 & 3.46 & 1.38 \\
Aware_vandalism & 48 & 4.0 & 3.35 & 1.41 \\
$\begin{array}{l}\text { Aware_article_revision_ } \\
\text { history }\end{array}$ & 46 & 3.5 & 3.30 & 1.47 \\
Aware_protected_pages & 47 & 3.0 & 2.72 & 1.53 \\
Aware_article_rank & 48 & 1.5 & 1.98 & 1.23 \\
\multicolumn{1}{l}{1 = not very aware, 3 = somewhat aware, $5=$ very aware } \\
\hline
\end{tabular}

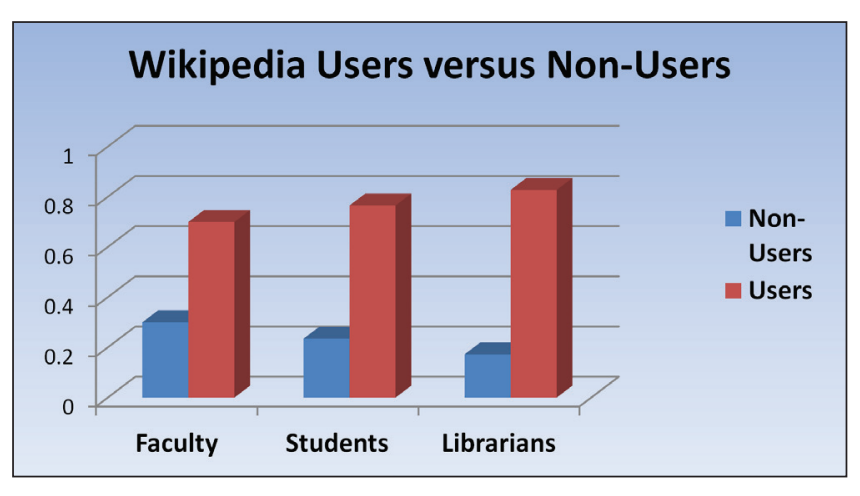

Figure 3. Wikipedia Users Versus Non-Users

are using Wikipedia more, proportionally, than either of the other user groups. These findings agree with those presented by Menchen-Trevino and Hargittai who studied college students' information seeking behaviors online and found that 77 percent of the study group accessed Wikipedia during information retrieval exercises. ${ }^{32}$

Table 7 gives usage statistics for the three groups under consideration.

A Kruskal-Wallis test for the medians yields no difference in usage patterns during the school year $\mathrm{H}(2)=3.533$, $\mathrm{p}>$ 0.05 , as well as for the non-school year $\mathrm{H}(2)=4.836$, $\mathrm{p}>$ 0.05 for the three groups.

Table 8 reports how each of the three groups utilize Wikipedia as an online information source. Table 8 indicates that the faculty in this study use Wikipedia for research (other than academic research) more than the other groups, while librarians use Wikipedia proportionally more than the other groups for independent learning, with faculty running a close second.

Table 9 reports the awareness statistics from the three user 


\section{FEATURE}

Table 7. Usage Statistics for Librarians, Faculty, and Students

\begin{tabular}{|c|c|c|c|c|c|}
\hline User group & Usage (times/week) & $\mathbf{n}$ & median & mean & $s$ \\
\hline \multirow[t]{2}{*}{ Librarians } & During School Year & 47 & 2.0 & 2.94 & 3.13 \\
\hline & Non-School Year & 47 & 1.0 & 2.12 & 3.10 \\
\hline \multirow[t]{2}{*}{ Faculty } & During School Year & 53 & 2.0 & 2.98 & 4.07 \\
\hline & Non-School Year & 53 & 1.0 & 3.02 & 4.37 \\
\hline \multirow[t]{2}{*}{ Students } & During School Year & 347 & 1.0 & 1.94 & 2.61 \\
\hline & Non-School Year & 352 & 1.0 & 1.94 & 4.32 \\
\hline
\end{tabular}

Table 8. Usage of Wikipedia

\begin{tabular}{l|cc|cc|cc}
\hline \multirow{2}{*}{ Type of Usage } & \multicolumn{2}{|c|}{ Librarians } & \multicolumn{2}{c|}{ Faculty } & \multicolumn{2}{c}{ Students } \\
& \multicolumn{2}{|c|}{ Yes } & No & Yes & No & Yes \\
Other research & $30(63 \%)$ & $15(31 \%)$ & $38(68 \%)$ & $18(23 \%)$ & $237(66 \%)$ & $119(33 \%)$ \\
Independent learning (pleasure) & $43(90 \%)$ & $5(10 \%)$ & $50(89 \%)$ & $6(11 \%)$ & $262(73 \%)$ & $92(26 \%)$ \\
\hline
\end{tabular}

Table 9. Awareness Categories

\begin{tabular}{|c|c|c|c|c|}
\hline \multirow[t]{2}{*}{ Category } & \multicolumn{3}{|c|}{ Medians } & \multirow[t]{2}{*}{ Kruskal Wallis } \\
\hline & Librarian & Faculty & Student & \\
\hline Aware_edited_anyone & 5.0 & 5.0 & 4.0 & $\mathrm{H}(2)=21.632 ; \mathrm{p}<0.05$ \\
\hline Aware_controversial & 4.0 & 4.0 & 4.0 & $\mathrm{H}(2)=0.886 ; \mathrm{p}>0.05$ \\
\hline Aware_vandalism & 4.0 & 3.0 & 3.0 & $\mathrm{H}(2)=2.701 ; \mathrm{p}>0.05$ \\
\hline Aware_article_revision_history & 3.5 & 3.0 & 3.0 & $\mathrm{H}(2)=8.059 ; \mathrm{p}<0.05$ \\
\hline Aware_protected_pages & 3.0 & 2.0 & 2.0 & $\mathrm{H}(2)=0.559 ; \mathrm{p}>0.05$ \\
\hline \multirow[t]{2}{*}{ Aware_article_rank } & 1.5 & 1.0 & 2.0 & $\mathrm{H}(2)=2.773 ; \mathrm{p}>0.05$ \\
\hline & \multicolumn{3}{|c|}{$1=$ not very aware, $3=$ somewhat aware, $5=$ very awar } & \\
\hline
\end{tabular}

groups. Table 9 indicates equal awareness in four of the six categories, with differences existing in the negative awareness category "Edited Anyone" — students are less aware that articles in Wikipedia can be edited by anyone, a fact that faculty and librarians are keenly aware of. Students and faculty are also less aware than librarians of the positive awareness category "Article Revision History" where all previous versions of a Wikipedia article are available.

Computing a "positive awareness" variable (= aware article revision history + aware protected pages + aware article rank) and a "negative awareness" variable (= aware edited anyone + aware controversial + aware vandalism) differences between the three groups can be analyzed. There is no difference in positive awareness between the groups, $\mathrm{H}(2)=1.641$, p > 0.05; while there is a difference in negative awareness between groups, $\mathrm{H}(2)=6.757, \mathrm{p}<0.05$, illustrating that faculty and librarians are more aware of the negative aspects of Wikipedia than are the students in these study groups.

\section{The Library and Librarians}

The final questions on the librarian survey concerned library support of Wikipedia and if the librarians surveyed were registered users of Wikipedia. Results from the librarians in this study revealed that 50 percent of the respondents work at a library that supports Wikipedia usage, while 37.5 percent do not, and 12.5 percent did not report either preference. It was also shown from this survey group that 16.7 percent of librarians work at a library that has a link to Wikipedia while 81.3 percent of librarians work at a library that does not have a link to Wikipedia, and 2.1 percent did not report, further indicating that while librarians use Wikipedia personally, it has yet to appear in the mainstream of professional librarianship. Finally, of this survey group, only 6.3 percent of the librarians are registered users of Wikipedia (have a login name and password) while 93.8 percent are not registered users, indicating that librarians in this sample group have not (yet) come to participate fully in the Wikipedia experience. 


\section{CONCLUSIONS}

A majority of librarians in this study are using Wikipedia (83 percent) which compares favorably to previous studies of faculty (70 percent) and students (77 percent). Librarians in this study are using Wikipedia for research (63 percent), but more for personal use (90 percent) and less in assisting library patrons (53 percent). This indicates that librarians in this study are cautious in advocating for Wikipedia in their work life, but utilize it in their personal information quests. The cautionary use of Wikipedia by these groups is most likely driven by awareness of the negative aspects of Wikipedia. These negative issues have given way to new editing policies and article creation policies in an attempt to strengthen the content of Wikipedia, which the user groups in this study were less aware of. Awareness of both aspects of a publicly created and utilized information resource will lead all groups to be better at online information literacy in the digital age. Librarians need to be aware of both positive and negative aspects of information resources on the web to assess their information content and to train patrons to evaluate web-based information resources critically.

Librarians in this study ranked the awareness issues the same as university faculty and students, with greater awareness of the negative features of Wikipedia and less awareness of the positive features of Wikipedia. These results agree with those of previous studies illustrating that librarians (as well as faculty and students) need to learn more about Wikipedia to assess the usefulness of this knowledge source in the age of the digital library.

Ranking systems exist for movies, academic journals, and for Wikipedia. The Wikipedia ranking system enables information seekers to view the quality of an article as a component of an information verification system as practiced by individuals who seek and use information. This ranking system requires that a user be logged-on to the Wikipedia site and enable the gadget for article rank. After this, when a user requests an article, an assessment of the article's quality is contained as part of the article header. The rankings are similar to a grade of the article's quality and range from stub (a very basic description of the topic) to C-class article, to B-class article, to A-class article, to FA-class article (encyclopedic quality). However, only 6.3 percent of the librarians in this study had accounts on Wikipedia and would be able to activate this gadget. Again, this indicates that librarians are not aware of the positive aspects of Wikipedia, thus cannot illustrate these to their patrons as they search for valid information online.

A surprising result from this research is that faculty and librarians seem to be using Wikipedia more than students in these study groups. This result was unexpected, as students in the twenty-first century are being classified as "digital natives" and are embedded in technology and information seeking activities, while librarians and faculty are perceived to be more skeptical about this information source. Further, figure 2 indicates that the school-age population is actively engaged in Wikipedia usage. This would suggest that librarians need to utilize, appropriately, Wikipedia to generate interest in information seeking and information literacy to further connect with their school-age patrons.

Library 2.0, as defined by Maness, ${ }^{33}$ is "communally innovative," meaning that as communities change, libraries must change and must allow the users (patrons) to change the library. Wikipedia as a top ten website (globally) and Wikipedia usage statistics as depicted in figure 2 indicate that this is a web resource netizens are embracing and librarians need to educate themselves to all aspects of this knowledge repository, not just the negative, high profile misuses of the site.

This study agreed with what other studies have indicated, that people (students, faculty, and librarians) are using Wikipedia. It also suggests that males are using Wikipedia more than females. This study benchmarked usage statistics for a librarian group and illustrated that negative awareness outweighs positive awareness with regard to issues surrounding Wikipedia. It is posited that this difference in awareness is a major factor in the usage (or not) of Wikipedia.

\section{References}

1. Alexa, "Global Top Ten," accessed August 2, 2011, www.alexa .com/topsites; eBizMBA, "Top 15 Most Popular web 2.0 Websites | July 2011," accessed August 3, 2011, www.ebizmba.com/articles/ web-2.0-websites; Quantcast, "Quantcast Site Rankings for USA," accessed August 3, 2011, www.quantcast.com/top-sites-1.

2. Johnny Snyder, "Wikipedia as an Academic Reference: Faculty and Student Viewpoints" in Proceedings of the Americas Conference on Information Systems, Lima, Peru, 2010, http://aisel.aisnet.org/cgi/ viewcontent . cgi article $=1015 \&$ context $=$ amcis 2010 .

3. Jack Maness, "Library 2.0 Theory: Web 2.0 and Its Implications for Libraries," Webology 3, no. 2 (2006): 1-9.

4. Ibid., 5 .

5. Pnina Shachaf, "The Paradox of Expertise: Is the Wikipedia Reference Desk as Good as Your Library?" Journal of Documentation 65, no. 6 (2009): 977-96.

6. Ibid., 987.

7. Ibid., 990

8. Theresa Anderson, "Information, Media, Digital Industries and the Library and Information Science Curriculum," Information Research 12, no. 4 (2007), accessed August 5, 2011, http://Infor mationR.net/ir/12-4/colis/colise04.html.

9. John East, "The Rolls Royce of the Library Reference Collection: The Subject Encyclopedia in the Age of Wikipedia," Reference \& Users Services Quarterly 50, no. 2 (2010): 162-69.

10. Ibid.

11. Kathy West and Janet Williamson, "Wikipedia: Friend or Foe?" Reference Services Review 37 (2009): 269-70.

12. Michael Stephens, "Exploring Web 2.0 and Libraries," Library Technology Reports 42, no. 4 (2006): 8-14.

13. Angela Rand, "Mediating at the Student-Wikipedia Intersection," Journal of Library Administration 50, no. 7-8 (2010): 923-32.

14. Johnny Snyder, "Wikipedia as an Academic Reference: Faculty and Student Viewpoints" in Proceedings of the Americas Conference on Information Systems, Lima, Peru, 2010.

15. Diane Murley, "In defense of Wikipedia," Law Library Journal 100, no. 3 (2008): 593-607.

16. Tony Stankus and Sarah Spiegel, "Wikipedia, Scholarpedia, and References to Books in the Brain and Behavioral Sciences: A Comparison of Cited Sources and Recommended Readings in Matching Free Online Encyclopedia Entries," Science \& Technology 


\section{FEATURE}

Libraries 29, (2010): 144-64.

17. Ibid., 145.

18. Jim Giles, "Internet Encyclopaedias Go Head To Head," Nature 438 (2005): 900-901; Stankus and Spiegel, "Wikipedia," 146.

19. Scholarpedia, "SPStatistics," accessed August 5, 2011, www.scholar pedia.org/article/Special:SPStatistics; Citizendium, "Welcome to Citizendium," accessed August 5, 2011, http://en.citizendium .org/wiki/Welcome_to_Citizendium; Wikipedia, "Featured article statistics," accessed August 5, 2011, http://en.wikipedia.org/wiki/ Wikipedia:Featured_article_statistics; Wikipedia, "Encyclopædia Britannica," accessed August 5, 2011, http://en.wikipedia.org/ wiki/Encyclop percentC3 percentA6dia_Britannica.

20. Philip Schreur, "The Academy Unbound-Linked Data as Revolution," Library Resources \& Technical Services 56, no. 4 (2012): 227-37.

21. Sook Lim and Nahyun Kwon, "Gender Differences in Information Behavior Concerning Wikipedia, an Unorthodox Information Source?" Library \& Information Science Research 32 (2010): 212-20.

22. Vivienne Waller, "The Search Queries that Took Australian Internet Users to Wikipedia," Information Research 16, no. 2 (2011): $1-19$.

23. Ibid.

24. Andy Field, Discovering Statistics Using SPSS (Los Angeles: Sage,
2009).

25. Brendan Luyt, Yasmin Ally, Nur Low, and Norah Ismail, "Librarian Perception of Wikipedia: Threats or Opportunities for Librarianship?" International Journal of Libraries \& Information Services 60, (2010): 57-64.

26. Ibid.

27. Brendan Luyt, Chia Zainal, Olivia Mayo, and Tan Yun, "Young People's Perceptions and Usage of Wikipedia," Information Research 13, no. 4 (2008): 1-11.

28. Compete.com, personal email to author, July 21, 2010.

29. Field, Discovering Statistics Using SPSS, 57.

30. Andrew LaVallee, "Only 13 Percent of Wikipedia Contributors are Women Study Says," Wall Street Journal, August 31, 2009, accessed August 15, 2011, http://blogs.wsj.com/digits/2009/08/31/only 13-of-wikipedia-contributors-are-women-study-says.

31. Johnny Snyder, "Wikipedia as an Academic Reference: Faculty and Student Viewpoints" in Proceedings of the Americas Conference on Information Systems, Lima, Peru, 2010.

32. Ericka Menchen-Trevino and Eszter Hargittai, "Young Adults' Credibility Assessment of Wikipedia," Information, Communication E Society 14, no. 1 (2011): 24-51.

33. Jack Maness, "Library 2.0 Theory: Web 2.0 and Its Implications for Libraries," Webology 3, no. 2 (2006): 1-9.

\section{APPENDIX. STATE UNIVERSITY SURVEY ON WIKIPEDIA USAGE一LIBRARIAN}

Your participation in this study will require completion of this questionnaire. This should take approximately 5 minutes of your time. Your participation will be anonymous and you will not be contacted again in the future. This survey asks questions about usage of Wikipedia and so constitutes no risk to you in responding. By completing and returning this questionnaire you are giving your consent to participate in my research. Your responses on the questionnaire are anonymous and you should not put any identifying information on it anywhere. You can stop filling out this survey at any time. I will be happy to answer any questions you have about this study. If you have further questions about this project or if you have a research-related problem, you may contact Dr. Writer at (xxx) xxx-xxxx. If you have any questions about your rights as a research participant you may contact the Director of Sponsored Programs at xxx-Xxxx. Preliminary results from a faculty and student survey can be found at http://aisel.aisnet.org/amcis2010/17.

\section{Demographic Information}

Gender: $\square$ Male $\square$ Female

Year of birth:

Library area: (please list job title)

1. Do you use Wikipedia, the online encyclopedia?

$\square$ Yes, please continue to the next question.

$\square$ No. Why not?

Thank-you for your participation. Please fold, tape, and mail (postage paid).

2. How often do you use Wikipedia in a typical school week? (fall and spring semesters) times in a school week

3. How often do you use Wikipedia in a typical Summer or Christmas break (i.e. non-school) week? times in a non-school week

4. How often do you assist library users in finding information on Wikipedia? times per week 
5. Do you use Wikipedia for research?

$\square$ Yes

$\square$ No

6. Do you use Wikipedia for pleasure (independent learning)?

$\square$ Yes

$\square$ No

7. How do you use Wikipedia?

$\square$ Initial research on a topic

$\square$ General topic review

$\square$ External links to topic

$\square$ Other:

\section{Please circle your response, where $1=$ very negatively, $3=$ neutral, and $5=$ very positively}

8. How do you view Wikipedia as a source of encyclopedic information?

$\begin{array}{lllll}1 & 2 & 3 & 4 & 5\end{array}$

9. How do you view Wikipedia as a source of general information?

$\begin{array}{lllll}1 & 2 & 3 & 4 & 5\end{array}$

Please circle your response, where $1=$ not very aware, $3=$ somewhat aware, and $5=$ very aware

10. Are you aware of controversial articles in Wikipedia?

$\begin{array}{lllll}1 & 2 & 3 & 4 & 5\end{array}$

11. Are you aware of vandalism in Wikipedia?

$\begin{array}{lllll}1 & 2 & 3 & 4 & 5\end{array}$

12. Are you aware that there are "protected pages" in Wikipedia?

$\begin{array}{lllll}1 & 2 & 3 & 4 & 5\end{array}$

13. Are you aware of the article rank feature in Wikipedia?

$$
\begin{array}{lllll}
1 & 2 & 3 & 4 & 5
\end{array}
$$

14. Are you aware of the article revision history in Wikipedia?

$$
\begin{array}{lllll}
1 & 2 & 3 & 4 & 5
\end{array}
$$

15. Are you aware that Wikipedia articles, unless protected, can be edited by "anyone?"

$\begin{array}{lllll}1 & 2 & 3 & 4 & 5\end{array}$

16. Does your library support the usage of Wikipedia?

$\square$ Yes

$\square$ No

17. Does your library's web page have a link to Wikipedia?

$\square$ Yes

$\square$ No

18. Are you a registered user of Wikipedia? (i.e., do you have a login name at the Wikipedia site?)

$\square$ Yes

$\square$ No 